\title{
ГОЛОС КАК ФОРМА ПРОЯВЛЕНИЯ СОЗНАНИЯ ПЕРСОНАЖА В ЦИКЛЕ ПЬЕС М.АРБАТОВОЙ «ПОЗДНИЙ ЭКИПАЖ»
}

\author{
Грета Ринкявичюте
}

\section{THE VOICE AS A FORM OF MANIFESTATION OF THE CHARACTER'S CONSCIOUSNESS IN THE CYCLE OF PLAYS BY M. ARBATOVA «THE LATE CREW»}

\author{
Hreta Rynkiavichutse
}

\begin{abstract}
Резюме: В данной статье рассмотрены аспекты функционирование Голоса в цикле пьес М.Арбатовой «Поздний экипаж». В результате анализа было выявлено, что появление (или отсутствие) Голосов в пьесах свидетельствует о глубоком кризисе личностной идентификации персонажей и раскрывает внутренние конфликты персонажей. В современной драматургии Голос является одной из форм проявления расщепления сознания и трансформации персонажей.
\end{abstract}

Ключевые слова: субстантивация Голоса, самоидентификация, трансформация персонажа, современная драматургия, Мария Арбатова.

Abstract: This article discusses the aspects of Voice functioning in the cycle of plays by M. Arbatova "the Late crew". As a result of the analysis, it was found that the appearance (or absence) The voices in the plays indicate a deep crisis of personal identification of the characters and reveal the internal conflicts of the characters. In modern drama, the Voice is one of the forms of manifestation of the splitting of consciousness and transformation of characters.

Key words: Voice substantiation, self-identification, character transformation, modern dramaturgy, Maria Arbatova.

DOI: $10.14712 / 9788076032088.10$

Проблема Голоса в современной русской драматургии на данный момент почти не исследована. Следует отметить, что Голос как явление можно рассматривать сразу в нескольких контекстах: культурологическом, психоаналитическом, лингвистическом, этическом. Прежде всего будем опираться на работы культурологов, которые занимались изучением Голоса. К ним относятся Младен Долар, Джуди Аппс и Жан-Пьер Сарразак. Некоторые аспекты функционирования голоса как субъекта речи в драме рассматриваются в статьях Анны Старшовой и Валентина Степанова, Натальи Малютиной. В нашей статье мы остановимся на психоаналитическом контексте проявления Голоса в пьесах Марии Арбатовой и контексте личностной самоидентификации персонажей. Обратимся к определению понятия «голос».

Джуди Аппс, известный специалист в области общения, отметила: «...изучение голоса это путешествие к себе, в поисках голоса вы находите себя» (Аппс 2012, 15).

В «Словаре современной и новейшей драмы» Жан-Пьер Сарразак (Сарразак 2007, 195) называет две сферы функционирования понятия «голоса»: 
1)физическое или фонетическое явление, вызванное высказыванием вслух;

2)голос драматурга или поэта, который так или иначе проявляет себя и распознаётся в произведениях для театра, которые используют «эффекты голоса» (Vinaver, Lemahier), он создаёт театр слов (Саррот) и нарушает интегральность (тождественность) голосов персонажей (Беккет, Новарина).

Нужно отметить, что Голос может быть субстантивирован в поэтике текста вследствие отказа автора/режиссёра от физического появления на сцене персонажа, присутствие которого заменяется Голосом. Голос в таком случае становится проявлением (или знаком) утраты целостности сознания персонажем. Приём замены физического присутствия субъекта речи Голосом часто используется в современной драматургии. Исследователь называет несколько форм проявления Голоса в пьесах: он помогает выразить позицию автора-нарратора (например, сказочника в пьесах-сказках), помогает «достроить» внутренний образ сознания персонажа и представить процессы (само) идентификации в монопьесах (в случае обнаружения Другого в Я персонажа)(Малютина 2014, 29).

Можно отметить, что подобная субстантивация Голоса наблюдается уже в пьесах русских драматургов 1990-х годов прошлого века, что можно связать с определенной новизной процессов личностной самоидентификации, к которым общество в те годы еще не было готово.

По мнению Анны Старшовой и Валентина Степанова, в современной драматургии, ведущей отсчет с 1990-х годов, появление Голоса тесно связано с трансформацией персонажа и кризисом его самоидентификации. Именно Голос и его тембр составляют воображаемую реальность повествования и заполняют собой всё пространство сознания персонажа единственную реальную "атмосферу» и картину действия. Голос может быть полноправным участником действия, а иногда даже главным действующим лицом (Старшова, Степанов 2015, 126).

В пьесах Голос часто является составляющей субъекта, даже если этот субъект отсутствует на сцене. Можно привести немало случаев (например, в пьесах С.Беккета), когда отсутствие источника голоса позиционируется как условие драматургического дискурса. Восприятие Голоса взаимосвязано с традицией сополагать Голос со взглядом. Следует отметить, что в современных пьесах часто используется субстантивация Голоса как субъекта речи (высказывания) в тексте, которая помогает его визуализировать (Долар 2018, 187).

Целью нашего исследования было выявление и анализ Голоса как формы проявления сознания персонажей в пьесах М. Арбатовой. Это обусловило и более частные задачи статьи: рассмотреть, как звучание Голоса способствует проявлению внутреннего конфликта в сознании персонажей, прежде всего, в ситуации идентификации: Я-Другой. Также постараемся выяснить, как появление Голоса связано с визуальным изображением индивидуальных особенностей персонажа.

Для анализа был выбран цикл в трёх радионовеллах М.Арбатовой, состоящий из трёх пьес: «Поздний экипаж», «Заслуженная училка», «Обряд инициации», в которых присутствует (или, как в третьей пьесе, отсутствует) Голос. Цикл пьес «Поздний экипаж» написан в 1990 году для радиотранслирования. Не характерный для драматических произведений жанровый подзаголовок «радионовеллы» указывает на способ трансляции и на характер жанрового посыла. Жанр новеллы отличается неожиданной развязкой: новеллистическим пуантом, что позволяет её эффектно передать посредством экспрессии звучащего голоса. Звучание Голоса приобретает в пьесах-радионовеллах особое функциональное значение, так как Голос является 
единственным инструментом, влияющим на сознание слушателей. В приведенных пьесах категория Голоса субстантивирована и обозначена как источник звучащей речи.

В качестве методологической основы исследования нами использованы работы М. Долара о феноменологии Голосе, который подробно рассматривает явление Голоса в лингвистическом, метафизическом, этическом, политическом, психоаналитическом и философском контекстах. Это дало нам понимание Голоса как одного из способов осознания индивидуальности. По специфическому индивидуальному тембру, резонансу, тону, ритму Голоса можно безошибочно распознать субъекта речи, в большинстве случаев, этот субъект является действующим лицом пьесы. Стоит отметить, что появление Голосов в пьесах М. Арбатовой можно рассматривать в контексте личностной самоидентификации персонажей. В пьесах «Поздний экипаж», и «Заслуженная училка» появление Голосов является индикатором кризиса самоидентификации главных персонажей, которое впоследствии приводит к расщеплению их сознания.

Пьеса М. Арбатовой «Поздний экипаж» начинается с цитаты из романа Томаса Манна «Лотта в Веймаре», посвящённого великому Иоганну Гёте. Это печальная история любви Гёте и Шарлотты Буфф, которая является прототипом образа Лотты в романе Иоганна Гёте «Страдания юного Вертера». Пьесу можно считать этюдом-картиной на тему несостоявшейся любви, а также на тему старости, увядания. Эпиграф является «авторской подсказкой» М. Арбатовой для читателей, которая сразу же помогает понять замысел автора и раскрыть основную коллизию произведения. Кроме того, эпиграф сообщает высказыванию лирическую тональность, которая характерна для всей пьесы. Само название пьесы и эпиграф говорят нам, читателям, о тесной взаимосвязи темы старости и увядания в пьесе. Жизнь скоротечна, и иногда от персонажей остаётся только Голос:

«....отречение и увядание живут в тесной близости, и вся действительность, всё сущее только зачахшее возможное» (Арбатова 2008, 476).

Действие пьесы начинается с характеристики тембра Голоса главной героини, что является одной из разновидностей номинации персонажа. Такая характеристика Голоса в ремарке отражает представления автора о нём. Реципиенту навязывается определённый взгляд на характер и состояние персонажей, содержащийся в описании их голосов. Читатель в своём воображении уже представляет главную героиню, а затем и её возлюбленного. Драматург таким образом придаёт пьесе эффект «загадки», ведь неизвестно, совпадут ли представления читателей с реальностью:

«Стук дамских каблуков и мужских башмаков. Скрип открывающейся дверцы. У неё пожилой, но глубокий голос, вспыхивающий от волнения молодыми нотками» (Арбатова 2008, 476).

Ожидания читателя в ходе развития диалога персонажей так и не оправдываются: «У него глухой красивый голос, то надменный, то обиженный» (Арбатова 2008, 476).

В пьесе М. Арбатовой главные участники действия определены по половому признаку (Он и Она), что связано с отсутствием каких-либо оснований для конкретизации в начале действия. Звучание Голоса связывается с индивидуализацией и автономией персонажа. Мы легко можем распознать человека по его голосу, специфическому индивидуальному тембру, резонансу, тону, ритму, мелодии, особенной манере произносить некоторые звуки (Долар 2018, 86).

В драматургии характеристика Голоса является средством психологического портретирования. Именно голос и его тембр составляют воображаемую реальность действия и 
заполняют собой все пространство сознания персонажа - единственную реальную «атмосферу» и картину действия:

«Пауза. Стук копыт и лёгкий скрип колёс свидетельствуют о том, что карета двинулась. У него глухой красивый голос, то надменный, то обиженный» (Арбатова 2008, 476).

В пьесе в очень общем виде обозначен характер «вечных» проблем взаимоотношений мужчины и женщины. Это магистральная тема творчества Марии Арбатовой:

Он: «Мужчина, плачущий у ног женщины, и мужчина, завоёвывающий её силою, - это разные люди».

Она: «А может быть, просто умирать от любви гораздо легче, чем потом сделать женщину счастливой в браке »(Арбатова 2008, 479).

Главная героиня в диалогах не акцентирует внимания на том, что она постарела, и только Голос передаёт её возраст. Она совсем не чувствует этого и находится «вне времени». Только в одной реплике главного персонажа подчёркивается её старость:

«Когда ты явилась в мой дом, я содрогнулся от боли, увидев, как отвратительно ты стара!» (Арбатова 2008, 479).

Стоит отметить также, что в пьесе Голос героини воспринимается её былым возлюбленным как инструмент:

"Только хотел сказать, что обнаружил удивительную вещь. Я видел лицо...но голос. Он остался тем же божественным инструментом, только исполняет теперь другую партию» (Арбатова2008, 479).

Значит, между звучанием голоса и психофизическим обликом героини отмечено существенное расхождение. Голос теперь не является знаком образа субъекта, а всего лишь знаком памяти.

Вся пьеса пронизана отчаянием и грустью главных персонажей вследствие несостоявшейся любви и нереализованных возможностей, которая передаётся читателям. Она пожертвовала своей красотой ради него:

«Доверчивость. Я ждала, что господь вознаградит меня за жертву» (Арбатова 2008, 479).

В свою очередь главный персонаж глубоко несчастен: он переживает из-за наступившей старости и несостоявшейся любви. Именно поэтому во время всего действия пьесы главный герой прячется в карете, тем самым, как бы пытаясь скрыться от старости и самого себя, что говорит о внутреннем конфликте персонажа:

«Потому что нельзя всерьёз относиться к старику, прячущемуся в карете от самого себя!» (Арбатова 2008, 479).

Стоит заметить, что пространственные перемещения в текстах пьес обязательно обозначаются автором (Старшова, Степанов 2015, 127).Также присутствуют знаки определенной эпохи. Хотя следует отметить, что историческое время передается весьма условно. В пьесе «Поздний экипаж» такими сигналами исторического времени могут служить упоминания о веере в руках женщины, постоянные обращения к свету как средоточию общественного мнения той эпохи:

Она: «Вы так размахиваете веером, точно собрались мне выбить глаза».

Он: «Я ждал тебя в карете, чтобы потом весь свет не надрывался от пересудов» (Арбатова 2008, 480).

В финале пьесы появляются 1-й, 2-й, 3-й мужские Голоса. Все они являются полноправными участниками действия. Возникает ощущение, что читателя хотят заставить вслушаться в происходящее, приглушить все остальные его органы чувств, кроме слуха. С одной 
стороны, Голоса усиливают напряжение читателей, а, с другой, - активизируют сосредоточенность на собственных процессах восприятия, рефлексии. Звучащие Голоса не только формируют действие, сценическое пространство, но и вызывают у зрителей определённый трансцендентный план погружения в некое таинство (Малютина 2013, 34).

В пьесе М. Арбатовой вечные отношения мужчины и женщины разворачиваются в карете, и только Голоса помогают идентифицировать личности персонажей, локализовать их отношения в системе координат конкретного времени и пространства. В финальной сцене читателю открывают, что сценку из жизни мужчины и женщины представляли великий Гёте и госпожа Кестнер перед крыльцом гостиницы (Старшова, Степанов 2015, 126):

1-й мужской голос: «Прошу вас, госпожа. Осторожно, здесь ступенька».

2-й мужской голос: «Госпожа Кестнер! Госпожа Кестнер! Вы были в театре? Боже, так ведь это карета великого Гёте!»

Она: «Прошу вас, распорядитесь, чтобы мне немедленно подали горячего кофе, видите, какя озябла» (Арбатова 2008, 481).

Не случайно М. Арбатова в финальной сцене пьесы инсценизирует общение главной героини с Голосами, что может быть связано с кризисом её личностной идентификации. Голос госпожи Кестнер сохранил признаки молодости: только он напоминает об её образе в прошлом. Именно благодаря появлению Голосов перед читателями открывается внутренняя драма героини: она глубоко несчастна, и никто не может этого изменить. Происходит разрушение самоидентификации и размытие границ сознания персонажа:

2-й мужской голос: «Госпожа Кестнер, вы были одна в театре?»

Она: «Перестаньте болтать о своих пустяках! Я так устала... И так несчастна...(Плачет)» (Арбатова 2008, 480).

Стоит отметить, что появление Голоса в пьесе является одним из средств «достраивания» действия, которое, несомненно, даёт прекрасную дополнительную возможность не только более детально и глубоко раскрыть характеры персонажей, но и целостно представить процессы внутреннего и внешнего действия персонажей. Именно Голоса передают внутренний конфликт героини, создавая экзистенциональное наполнение действия. Не случайно М. Арбатова добавляет мужские Голоса в пространство действия именно в конце пьесы. Таким образом, несколько изменяется психологическая характеристика персонажа, что говорит о внутреннем конфликте главной героини. В финале пьесы конфликт не разрешается, тем самым подчёркивается безнадёжность ситуации и невозможность что-либо уже изменить. И Он, и Она встретились уже тогда, когда стали другими: не было пылкой Лотты и молодого Гёте.

Явление субстантивации голоса прослеживаем и в следующей пьесе цикла. В самом начале пьесы «Заслуженная училка» появляется описание интонации Голоса главной героини. Стоит отметить, что интонация - это ещё один способ осознания голоса, поскольку особенный тон голоса, его специфические мелодика и модуляции, ритм и изменения интонации могут повлиять на смысл высказывания (Долар 2018, 84):

«У неё немолодой голос со скрипящими властными интонациями» (Арбатова 2008, 481).

Таким образом, автор сразу же навевает читателю неприятное впечатление о ней. Читатели постепенно знакомятся с главной героиней. Она - заведующая детским домом, заслуженный работник образования. Судя по её высказываниям, у неё нет сомнений в правильности своего отношения к людям, но по тому, как она говорит и общается с ними, можно сделать вывод о внутреннем конфликте с самой собой и о её детской травме. Речь идёт об обиде из-за отсутствия любви матери: 
Она: « Ну всё, пошла, теперь понесёт по селу! Плевать на них. Моя невестка - моё дело. Ещё она по моим полкам лазила, ищейка чёртова! Между прочим, когда женился, у меня совета не спрашивал! На свадьбу пригласил, и делай что хочешь. Денег им слали нечитано, а где любовь, где уважение? "Кончилось ваше время!» Я ведь всего в жизни сама добивалась. Мать меня и сестёр, чуть что, за косы до полу гнула! На одной картошке выросла! Заслуженной учительницей стала!» (Арбатова 2008, 487-488)

Казалось бы, главная героиня в силу профессии и жизненного опыта должна быть открытой и любить детей, но, на самом деле, она никого не любит. Её главная проблема состоит в том, что она не любит ни себя, ни невестку, ни своих детей. Это отчётливо проявилось в той ситуации, когда главная героиня обсуждает с соседкой то, что её невестка заболела вместе с детьми:

Старушечий голос: «Михаловна, я к тебе на двор зашла, а там твоя молодая как коза с земли подорожник рвёт. Мальцы оба в жару, сама вся бледная, аж шатается, а в избе пусто, да ты на огороде! А у тебя в избе ни мёду, ни липы, ни малины сухой!»

Она: «Всё у неё есть, Настасья Кирилловна. Это она так, чтоб свекровь перед соседями опозорить. Городская» (Арбатова 2008, 487).

Не случайно по мере развития действия в пьесе появляются три Голоса (Детский, Мужской, Старушечий), которые общаются с главной героиней. В диалоге с ними проявляется установка главной героини на общение с ребёнком, взрослым либо пожилым человеком. В звучании голоса отражены гендерные отличия (он принадлежит мужчине, женщине или девочке). При этом не важными становятся межличностные контакты и индивидуальная характеристика персонажа, представленного только посредством звучащего голоса. С точки зрения автора, видимо, не имеет значения, какой это ребёнок и какой это мужчина. Повидимому, персонажи высказываются только благодаря тому, что их слышит и воспринимает Героиня. Сами по себе как характеры или индивиды они не интересны и не важны для автора. Появление Голосов связано с активизацией процессов идентификации главной героини, в сознании которой они появляются. Голоса раскрывают психологический конфликт персонажа с самой собой:

«Я ведь деньги на книжку ложила, чтоб этот дом купить! Чтоб всем было хорошо! Чтоб мы с Вовой могли летом побыть здесь, а не в отравленном городе, чтоб сын из Москвы приехал, чтоб дети яблок поели... Я хотела, чтоб всем было хорошо. Мне шестьдесят лет, я всю жизнь работала не покладая рук!» (Арбатова 2008, 488)

Стоит обратить внимание на то, что главная героиня разговаривает с Голосами (Детским, Мужским, Старушечьим), работая в огороде. Она не смотрит, кто говорит и, таким образом, не визуализирует услышанные ею Голоса. Главная героиня устанавливает идентификацию односельчан по звучанию Голоса, но при этом, по сути, идентифицирует себя (так как и в «Позднем экипаже»). Она слышит Детский Голос, значит это ребёнок. В драматургии одной из форм раскрытия психологического состояния персонажа является звучание голоса. Почти безошибочно можно распознать человека по его голосу, тембру, тону. Голос, как отпечатки пальцев, түт же узнаваем и опознаваем. У главной героини проявляется расщепление сознания во время общения с "Голосами». Диалоги с Голосами дают читателям более глубокое представление о главной героине и раскрывают внутренний конфликт с собой. Именно во время разговоров с Голосами осуществляются процессы роста личностного самосознания главного персонажа. Возможно, что сам факт того, что она воспринимает голоса, а не людей, которым они принадлежат, уже говорит об её отношении к ним. 
В конце пьесы мужской Голос сообщает главной героине, что она выдёргивает огурцы вместо сорняков:

Она: «Этого не может быть... Это какая-то накладка. Я смотрела в справочнике, какие у огуриа... Это просто накладка...Глупость какая-то: огурцы и сорняки...Это же так просто. Почему они совсем одинаковые?.. Это какая-то накладка» (Арбатова 2008, 489).

Такое поведение главной героини свидетельствует о сильном эмоциональном напряжении, в котором она всё время пребывала. Видимо, поэтому её сознание было направлено на внутренние психологические проблемы, и она не заметила, что прополола совсем не то, что хотела. В развязке, которая остаётся открытой, мы не видим возможностей для разрешения внутренних конфликтов в душе и сознании главной героини.

В пьесах М.Арбатовой «Поздний экипаж», «Заслуженная училка» Голоса не являются полноценными персонажами пьесы, а лишь условными конструктами, помогающими понять внутренние драмы главных героев. Автор в пьесах проявляет свою компетенцию только в ремарках. Так, в пьесе «Заслуженная училка» автор проявляет себя в характеристиках Голоса. Автор различает Детский Голос, Мужской и Старушечий, тем самым указывая на гендерные и возрастные различия в общении. Чаще всего эти характеристики отражают важную черту психологического состояния персонажа:

«У неё пожилой, но глубокий голос, вспыхивающий от волнения молодыми нотками» («Поздний экипаж») (Арбатова 2008, 476).

«У него глухой красивый голос, то надменный, то обиженный» («Поздний экипаж») (Арбатова 2008, 476).

«У неё немолодой голос со скрипящими властными интонациями» («Заслуженная училка») (Арбатова 2008, 481).

Голоса в двух пьесах исходят как будто из невидимого пространства и способствуют раскрытию внутреннего состояния главных героев. Наблюдаем эффект некой «интимности», так как раскрывается то, что скрыто от внешних проявлений; «оголяются» затаённые, скрытые в подсознании внутренние проблемы персонажей. Именно появление Голосов в двух пьесах лишает главных персонажей автономии, что приводит читателей к более ясному пониманию их конфликта с собой.

В пьесах «Заслуженная училка» и «Поздний экипаж» М. Арбатовой Голос становится речью и языком. Его звучание совпадает с самим процессом высказывания. Голос выступает как «агент» акта высказывания и составляет так называемую нить, держащую их вместе. Если означающие (семантические составляющие высказывания) образуют цепочку, то Голос вполне может быть тем, кто их нанизывает. Поскольку процесс высказывания указывает на место и характер субъективного в языке, то Голос находится в ближайшей связи с самим понятием субъекта.

В третьей пьесе М. Арбатовой «Обряд инициации» не наблюдаем каких-либо проявлений голоса, авторского внимания к явлению голосового звучания. Два главных персонажа - это молодой человек, приезжающий в деревню купить дом, и старуха Ганя. Сюжет разворачивается при помощи диалогов - им отведена большая роль в действии пьесы. Голос не появляется в пьесе, так как главные персонажи, участвующие в традиционном диалоге, обладают индивидуальностью, которая проявляется на протяжении всей пьесы. Если в пьесах «Поздний экипаж» и «Заслуженная училка» М. Арбатовой трансформации происходили с главными героинями, то в «Обряде инициации» изменение сознания и переоценка ценностей происходят у молодого человека: 
Деловой: «Вот тебе пятьсот рублей, побожись, что больше мака сеять не будешь!»

Cmapyxa: «Чого?»

Деловой: «В аду за мак гореть будешь».

Старуха: "Да я всего только грядочку! Маркоманы-то мени то покосют, то сено сгребут.

Одна я, Сашко!»

Деловой: «Приеду - забор тебе починю».

Старуха: «Почини, Сашко» (Арбатова 2008, 501).

Таким образом, у главного персонажа происходит переворот в сознании, и он получает новый опыт, к приобретению которого, возможно, он не был готов. М. Арбатова не случайно называет данную пьесу «Обряд инициации», ведь инициация - это обряд, знаменующий переход индивидуума на новую ступень развития в рамках какой-либо общественной группы или мистического общества. То есть можно предположить, что молодой человек неожиданно для себя «взрослеет» и теперь по-другому смотрит на жизнь.

Действие в пьесе «Обряд инициации» также характеризуется открытым финалом. Главные персонажи прощаются и понимают, что, возможно, они никогда больше не встретятся: Деловой: «До свидания, баба Ганя. Я приеду».

Старуха: «Я тебя ждать буду. Гляди не обмани» (Арбатова 2008, 502).

Подводя итоги, стоит отметить, что цикл из трёх пьес не случайно назван «Поздний экипаж». Это подчёркивает общую тему всех пьес - тему старости и одиночества. Каждая из главных героинь находится в преклонном возрасте и, по-своему, несчастна и одинока. Появление Голосов в пьесах «Поздний экипаж» и «Заслуженная училка» свидетельствует о глубоком кризисе личностной идентификации персонажей. В третьей пьесе отсутствие Голоса объясняется ярко выраженной индивидуальностью главных персонажей. Если в пьесе «Поздний экипаж» появляется Мужской и Женский Голоса, то в пьесе «Заслуженная училка» добавляются ещё Старушечий и Детский, то есть представлены гендерные и возрастные отличия Голосов. В «Позднем экипаже» лейтмотивом проходит тема несостоявшейся любви. Общим элементом трёх пьес является рефлексия главных героинь, которая раскрывается по мере развития сюжета. Голоса в этих пьесах играют ключевую роль: при помощи них М. Арбатова передает внутренние конфликты в сознании главных персонажей и нарушения в процессе самоидентификации персонажей. Таким образом, можно сделать вывод, что появление Голосов в пьесе является способом представления гротескной трансформации сознания персонажей в современной драматургии.

\section{Использованная литература/ References}

\section{Печатные источники:}

АРБАТОВА М.И. (2012): Старые пьесы о главном. Москва: Издательство «АСТ МОСКВА», 2008, 731, ISBN 97859713-91760

АППС Дж. (2012): Чтобы слушали и слышали! Влияние вашего голоса. Питер, 2012, ISBN 9785459007602. долАР М. (2018): Голос и ничего больше, Санкт-Петербург: Издательство Ивана Лимбаха 2018, 384, ISBN 9785890593184.

МАлЮТИНА Н.П. (2014): Пластика персонификации голоса как катализатор действия в современной драме. In Новейшая драма рубежа XX - XXI веков: проблема действия. Самара: Издательство Самарский государственный университет, 2014, с.29-30, ISBN 978-5-86465-621-1. 
СТАРШОВА А.П. , СТЕПАНОВ В.Н. (2015): Трансформация персонажа в современной драматургии. In Верхневолжский филологический вестник, Ярославль, 2015, №1, 124-131, ISSN 2499-9679.

SARRAZAC J. (2007): Słownik dramatu nowoczesnego i najnowszego pod red.J. P.Sarrazaca/tłum.M.Borowski.M.Sugiera, Kraków:Księgarnia Akademicka, 2007.

\section{Профиль автора:}

Грета Ринкявичюте, магистр факультета русской филологии

Научные интересы: современная драматургия, театр, перформанс, творчество Марии Арбатовой e-mail: tamtadziewczyna99@gmail.com

Место работы: Университет в Белостоке, г. Белосток, Пл. Независимого объединения студентов 1, 15-420,

Польша

\section{Author's profile:}

Hreta Rynkiavichutse, master of the faculty of Russian Philology

Research interests: modern dramaturgy, theater, performance, literary works of Maria Arbatova e-mail: tamtadziewczyna99@gmail.com

Place of work: University of Bialystok, Bialystok, Plac NZS 1 Street, 15-420, Poland 